\title{
Review Article \\ The Importance of Velocity Acceleration to Flow-Mediated Dilation
}

\author{
Lee Stoner, ${ }^{1}$ Joanna M. Young, ${ }^{2}$ Simon Fryer, ${ }^{3}$ and Manning J. Sabatier ${ }^{4}$ \\ ${ }^{1}$ School of Sport and Exercise, Massey University, Wellington, New Zealand \\ ${ }^{2}$ Lipid and Diabetes Research Group, Diabetes Research Institute, Christchurch Hospital, Christchurch, New Zealand \\ ${ }^{3}$ School of Sciences and Physical Education, University of Canterbury, Christchurch, New Zealand \\ ${ }^{4}$ Division of Biological Sciences, Clayton State University, Morrow, GA, USA
}

Correspondence should be addressed to Lee Stoner, dr.l.stoner@gmail.com

Received 19 September 2011; Accepted 12 October 2011

Academic Editor: Arnon Blum

Copyright (c) 2012 Lee Stoner et al. This is an open access article distributed under the Creative Commons Attribution License, which permits unrestricted use, distribution, and reproduction in any medium, provided the original work is properly cited.

The validity of the flow-mediated dilation test has been questioned due to the lack of normalization to the primary stimulus, shear stress. Shear stress can be calculated using Poiseuille's law. However, little attention has been given to the most appropriate blood velocity parameter(s) for calculating shear stress. The pulsatile nature of blood flow exposes the endothelial cells to two distinct shear stimuli during the cardiac cycle: a large rate of change in shear at the onset of flow (velocity acceleration), followed by a steady component. The parameter typically entered into the Poiseuille's law equation to determine shear stress is time-averaged blood velocity, with no regard for flow pulsatility. This paper will discuss (1) the limitations of using Posieuille's law to estimate shear stress and (2) the importance of the velocity profile-with emphasis on velocity acceleration - to endothelial function and vascular tone.

\section{Introduction}

The pathological complications of atherosclerosis, namely, heart attacks and strokes, remain the leading cause of mortality in the Western world [1]. Preceding atherosclerosis is endothelial dysfunction [2-4]. The flow-mediated dilation (FMD) test has emerged as the noninvasive standard for assessing in vivo endothelial function [5]. Despite its potential, the validity of the FMD test has been questioned due to the lack of normalization to the primary stimulus, shear stress [6-10]. Fortunately, the ultrasound technology used to conduct the FMD test can also provide estimates of shear stress [11]. Typically, shear stress is estimated by employing a simplified mathematical model based on Poiseuille's law. More sophisticated approaches using magnetic resonance imaging are available, but are beyond the reach of most clinical studies since such techniques are not readily available, are too expensive, and are technically challenging and time consuming [12-14].

Little attention has been given to the most appropriate blood velocity parameter(s) for calculating shear stress. The pulsatile nature of blood flow exposes the endothelial cells to two distinct shear stimuli during the cardiac cycle: a large rate of change in shear at the onset of flow (velocity acceleration), followed by a steady shear component. In vitro studies suggest that these two distinct fluid stimuli regulate short- and long-term endothelial function via independent biomechanical pathways [15-17]. The parameter typically incorporated into the Poiseuille's law equation for shear stress is time-averaged blood velocity, that is, blood velocity averaged across the cardiac cycle, with no regard to flow pulsatility. This paper will discuss (1) the limitations of using Posieuille's law to estimate shear stress and (2) the importance of the velocity profile-with emphasis on velocity acceleration-to endothelial function and vascular tone.

\section{Flow-Mediated Dilation}

The FMD test is a noninvasive method of evaluating endothelial function. A number of authors have developed standardized guidelines for conducting this test [18-20], including a recent article by Thijssen and colleagues [21]. The 
standard FMD test, as first described by Celermajer et al. [22], places a pneumatic tourniquet forearm just below the elbow and distal to imaged brachial artery. The tourniquet is inflated to a suprasystolic blood pressure for 5 minutes. Rapid deflation of the tourniquet instigates increased blood flow (reactive hyperemia) to the oxygen starved forearm muscles, with a subsequent increase in flow through the upstream brachial artery. The flow-induced increase in shear stress results in vasodilation of the brachial artery. The magnitude of FMD, expressed as the percentage increase in diameter above rest, is used to represent endothelial health.

\section{Shear Stress}

Despite the term flow-mediated dilation, shear stress (see Figure 1) is the established stimulus for FMD $[6,7,10,23-$ 28]. Shear stress is determined by red blood cells moving close to the endothelial cells. As the fluid particles "travel" parallel to the wall, their velocity increases from zero at the wall to a maximum value at some distance from the wall. This leads to the establishment of a gradient, which is defined as shear stress (Figure 2). Shear stress therefore acts at a tangent to the wall to create a frictional force at the surface of the endothelium. The endothelial cells are equipped with mechanosensors to detect this stress [29-38].

To maintain physiological levels of vessel wall shear stress, vascular tissues respond with acute adjustments in vascular tone through vasodilatation [39]. Vasodilation reflects alterations in the rate of production of endothelial-derived mediators, including nitric oxide $(\mathrm{NO})$, prostacyclin $\left(\mathrm{PGI}_{2}\right)$, and endothelial-derived hyperpolarizing factor (EDHF), which act locally to modulate vascular smooth muscle tone.

\section{Shear Stress Mechanotransduction}

The endothelium is a complex mechanical signal-transduction interface between the vessel wall and the flowing blood. Mechanotransduction is the interaction between shear stress-induced biomechanical forces and endothelial cell function. Exactly how these biomechanical forces are sensed by endothelial cells remains unclear. Two models of mechanotransduction have been demonstrated so far, a localized model and a decentralized model.

4.1. The Localized Model. The mechanoreceptor, like other receptors, is considered to be located in the cell membrane (Figure 3). Channels (i.e., $\mathrm{K}^{+}, \mathrm{Na}^{+}$, and $\mathrm{Cl}^{-}$) located in membrane respond to changes in shear stress. Because ion channel activation is one of the fastest known endothelial responses to flow, these ion channels are the proposed flow sensors [29$31,33,34,40]$. The flow-sensitive ion channel first identified in endothelial cells was an inward-rectifying $\mathrm{K}^{+}$channel, whose activation leads to hyperpolarization of the cells membrane $[35,36]$. The second type of flow-sensitive ion channel, more recently discovered, is an outward-rectifying $\mathrm{Cl}^{-}$ channel $[37,38]$. The change in membrane potential, associated with the activation of these ion channels, alters the electrochemical gradient for $\mathrm{Ca}^{2+}$ transport across the endothelial cell membrane. This has been shown to provide a mechanism of direct interaction between flow-sensitive ion channels and $\mathrm{Ca}^{2+}$-dependent pathways $[37,38]$.

The $\mathrm{Cl}^{-}$and $\mathrm{K}^{+}$channels are activated independently $[37,38]$. Activation of $\mathrm{Cl}^{-}$channels leads to cell membrane depolarization; this follows the initial $\mathrm{K}^{+}$channel-mediated hyperpolarization. The fact that hyperpolarization precedes depolarization, in spite of the larger electrochemical driving force for $\mathrm{Cl}^{-}$than $\mathrm{K}^{+}$, suggests that flow-sensitive $\mathrm{Cl}^{-}$channels attain maximal activation more slowly than flow-sensitive $\mathrm{K}^{+}$channels. The notion that $\mathrm{K}^{+}$channels respond to shear stress more rapidly than $\mathrm{Cl}^{-}$channels is expected to be particularly relevant for situations where a time-varying shear stress may activate one or both channels depending on the time constant characterizing the changes in shear stress.

There is mounting evidence that flow-sensitive $\mathrm{K}^{+}$and $\mathrm{Cl}^{-}$channels play a central role in regulating overall endothelial responsiveness to flow [41-43]. This notion is supported by data demonstrating that interference with these candidate mechanosensors affects downstream gene and protein regulatory responses. For instance, pharmacological antagonists of flow sensitive $\mathrm{K}^{+}$and $\mathrm{Cl}^{-}$channels greatly attenuate or entirely abolish shear stress-induced release of cyclic guanosine monophosphate (cGMP) [41] and NO, downregulate endothelin-1 [42], and induce $\mathrm{Na}-\mathrm{K}-\mathrm{Cl}$ cotransport protein [43].

4.2. The Decentralised Model. This model suggests that the mechanical forces acting on the luminal side of endothelial cells are transmitted through the cytoskeleton to other sites within the cell [44]. The endothelial cell can be viewed as a membrane stretched over a frame composed of intermediate filaments and actin fibers which transverse the cells and end in adhesion complexes (Figure 3). Even under nonstimulated conditions, the entire endothelial cytoskeleton is maintained under tension, and in response to an externally applied stimulus intracellular tension is redistributed over the cytoskeleton network. These forces are especially sensed at the basal adhesion points, where the endothelial cell is attached to the extracellular matrix, cell junctions, and the nuclear membrane [30]. So it is conceivable that the application of a stressor activates signal transduction cascades without the need of a specific shear stress or stretch receptor. Integrins connected to the cytoskeleton have been related to this mechanism of mechanoreception [45].

\section{Shear Stress Estimation}

Clinical studies in humans, including FMD studies, typically estimate shear stress by employing a simplified mathematical model based on Poiseuille's law, where shear rate equals

$$
\text { Shear rate }(\gamma)=\frac{2(2+n) v}{d},
$$

where $d$ is the internal arterial diameter, $v$ is time averaged mean blood velocity, and $n$ represents the shape of the velocity profile. For a fully developed parabolic profile, $n$ is 2 .

Poiseuille's law assumes that (1) the fluid (blood) is Newtonian; (2) blood flows through a rigid tube; (3) whole blood viscosity represents viscosity at the vessel wall and is 


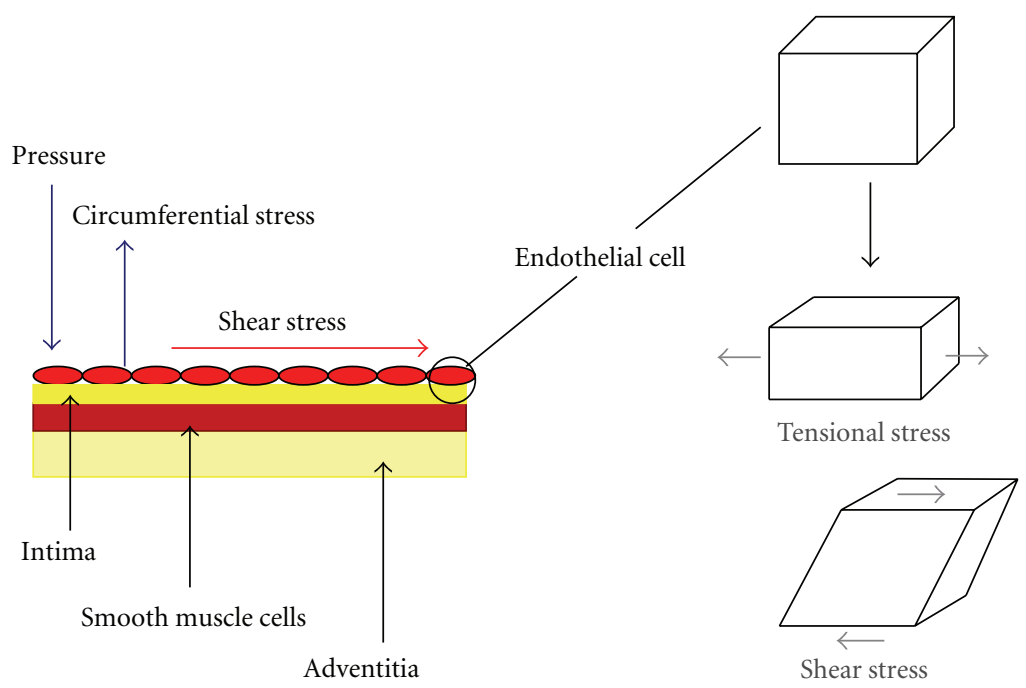

FIGURE 1: Haemodynamic Stress. Shear stress results in parallel deformation, as opposed to normal stress or force, which when applied to an object induces normal (direct) deformation.

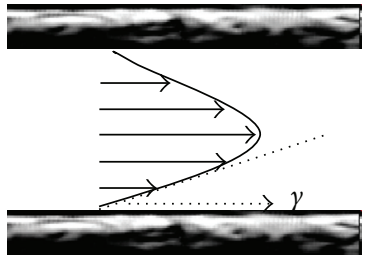

(a) High parabolic velocity

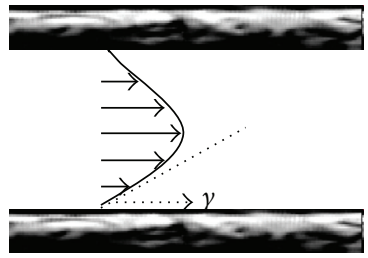

(b) Low parabolic velocity

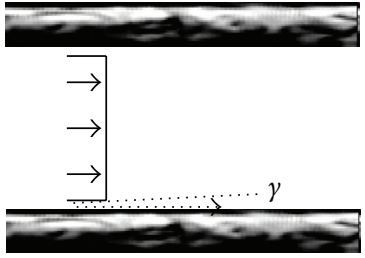

(c) Plug velocity

Figure 2: Determination of Shear Rate $(\gamma)$. As fluid particles "travel" parallel to the vessel wall, their average velocity increases from a minimum at the wall to a maximum value at some distance from the wall, resulting in a gradient of velocities. The actual shear rate at the vessel wall is determined by shape of the velocity profile. Shear stress-induced deformation of the endothelial cells is detected by mechanoreceptors on the cell membrane.

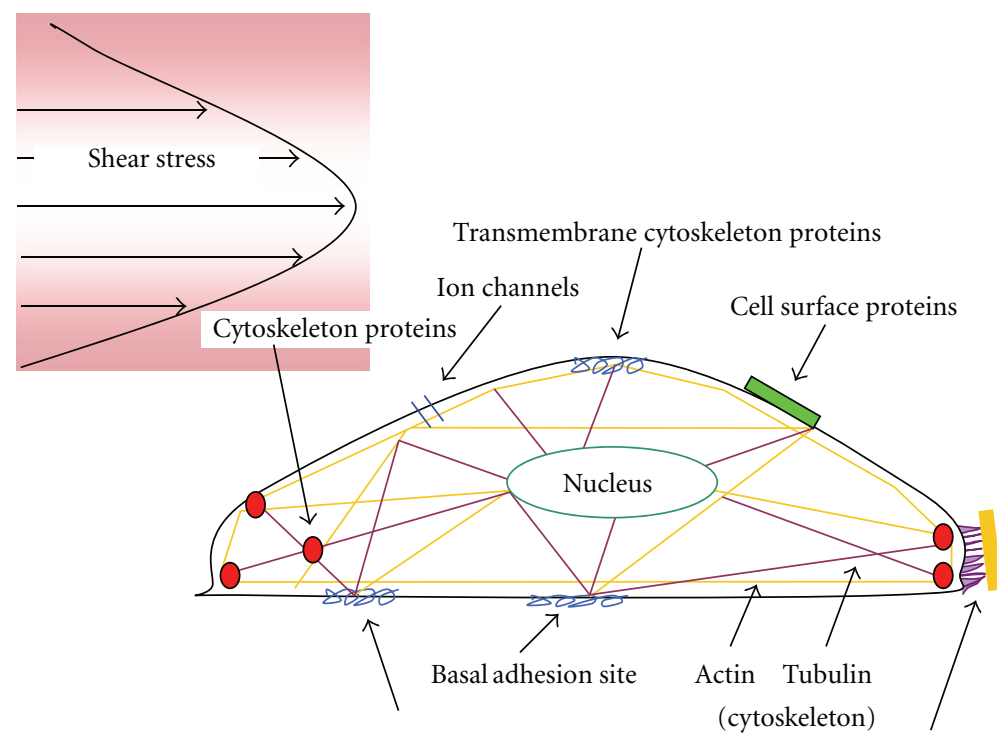

Cell contact to extracellular matrix

Intracellular contact proteins

FIgure 3: Putative Mechanisms of Mechanotransduction. The localized model for shear stress mechanotransduction assumes that shear stress sensors are located in the cell membrane. Ion channels are the proposed flow sensors. The decentralized model suggests that the mechanical forces acting on the luminal side of the endothelial cells are transmitted through the cytoskeleton to other sites in the cell. Integrins connected to the cytoskeleton have been related to this mechanism of mechanoreception. 
linearly proportional to shear rate; (4) the velocity profile is parabolic; (5) mean blood velocity adequately defines the shear stimulus.

First, although blood is a non-Newtonian fluid at low shear rates (smaller than approx. $100 \mathrm{~s}^{-1}$ ) [46] in vivo, shear stress in large arteries, particularly at the endothelial surface, is generally considerably larger than this threshold value so that the effect of the non-Newtonian behavior does not appear to be pronounced. Second, blood vessels are distensible, meaning that wall shear rate may be $\sim 30 \%$ less in a distensible artery as compared with a rigid tube [47].

Third, the magnitude of shear stress, to which the endothelial cell is subjected, is given by the product of the dynamic viscosity of blood and shear rate. Viscosity is an internal property of a fluid that offers resistance to flow. For Newtonian fluids, shear rate and viscosity are directly related. However, the relationship between shear rate and viscosity is nonlinear for non-Newtonian fluids. Human in vivo studies are usually limited to whole blood measurements of viscosity. These measurements overestimate the viscosity at the wall of the vessel. Less red blood cells travel along the artery wall, where, in addition to a thin layer of plasma, blood platelets are traveling [48]. Red blood cells tend to stream in the center of the vessel, resulting in higher viscosity in the center and thereby reducing the shear stress gradients at the vessel wall.

It is worth noting that shear stress assessments do not seem to result in conclusions different from shear rate assessments alone [49]. This may be explained by two factors: (1) sources of error from whole blood viscosity estimates and (2) blood viscosity exhibits low intrasubject variability [50], particularly among a healthy, homogenous group. Shear rate has been used as a surrogate measure of shear stress in a number of previous studies [49-53]. Nonetheless, the relationship between vascular homeostasis and blood viscosity is complex [54]. Further study is required to determine the influence of blood velocity on shear stress estimations, particularly for populations exhibiting cardiovascular risk factors known to effect blood viscosity.

Fourth, in arteries, the velocity profile will not develop to a full parabola as a consequence of flow unsteadiness and short vessel entrance lengths. In both arteries and arterioles, the velocity profiles are actually flattened parabolas ([13], see Figure $2 \mathrm{~B})$. In the common carotid artery, mean wall shear stress is underestimated by a factor of 2 when assuming a parabolic velocity profile [55]. In the brachial artery, the underestimation is less pronounced, likely due to a more parabolic velocity profile in this artery, that is, $n$ (velocity profile) is closer to 2 ([55], see Figure $2 \mathrm{~A}$ ). However, this may only be true for resting conditions; occurrence of flow turbulence is possible during reactive hyperemia [56].

Fifth, for a given mean blood velocity, the flow profile can vary dramatically due to the pulsatile nature of circulation [57-59]. Blood flow pulsatility results in endothelial cells being exposed to two distinct shear stimuli during the cardiac cycle: a large rate of change (velocity acceleration) in shear at the onset of flow, followed by steady shear. In vitro studies suggest that these two distinct stimuli regulate short- and long-term endothelial function via independent biomechanical pathways [60-67]. Mean blood velocity is

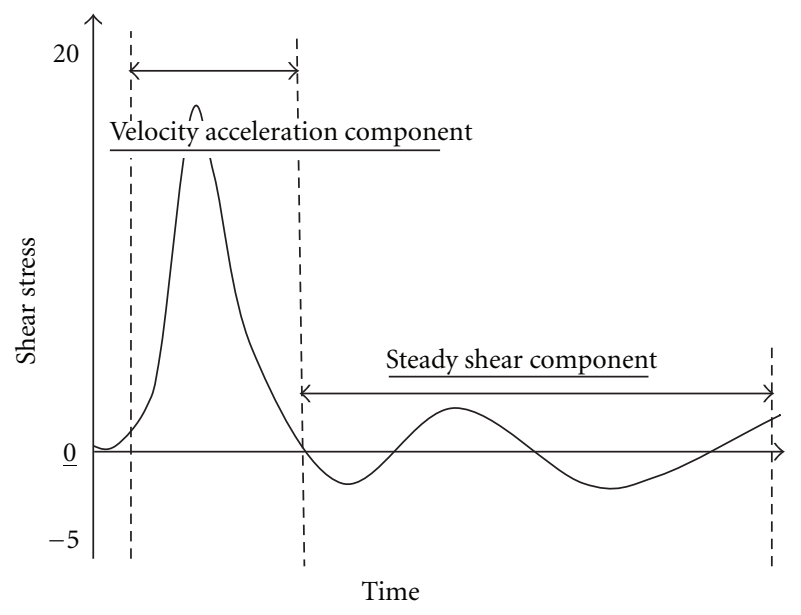

FIgURE 4: Acceleration and Steady Shear Components. The normal brachial arterial signal is triphasic, corresponding to the (1) rapid blood flow during systole, resulting in velocity acceleration, (2) initial reversal of blood flow in diastole, and (3) gradual return of forward flow during late diastole, resulting in steady shear component.

therefore unlikely to characterize the shear stimulus, particularly during hyperemic conditions.

\section{The Importance of the Velocity Profile to Shear Stress Mechanotransduction}

The earliest studies investigating the effects of shear stress on endothelial function did so by assessing endothelial cell responses to high versus low shear stress. This was until Davies et al. [68], in 1986, provided evidence that the time-averaged shear stress alone could not explain the pathological behavior of endothelial cells exposed to complex flow patterns. Subsequent studies [57, 66, 69-75] have shown that vascular endothelial cells respond not only to the time-averaged shear stress, but respond differently to different patterns of flow.

The cyclic nature of the beating heart creates pulsatile flow conditions in all arteries. The heart ejects blood during systole and fills during diastole. These cyclic conditions create relatively simple monophasic flow pulses in the upper region of the aorta [76]. However, pressure and flow characteristics are substantially altered as blood circulates through the arterial tree. Figure 4 shows an example of a typical brachial artery blood velocity profile. The normal brachial arterial signal is triphasic, corresponding to (1) rapid blood flow during systole, (2) initial reversal of blood flow in diastole, and (3) gradual return of forward flow during late diastole.

The blood flow profile in the aorta is predominately governed by the force of blood ejected from the heart [77]. However, in the periphery, the blood flow profile becomes more complex as a result of the energy transfer between the heart and arteries. The heart generates forward-traveling wave energy that propagates through the arteries to maintain tissue and organ perfusion for metabolic homeostasis. An individual forward-traveling waveform, generated by the heart at the beginning of systole, initiates flow and increases pressure in the arteries. Although most of the wave energy 


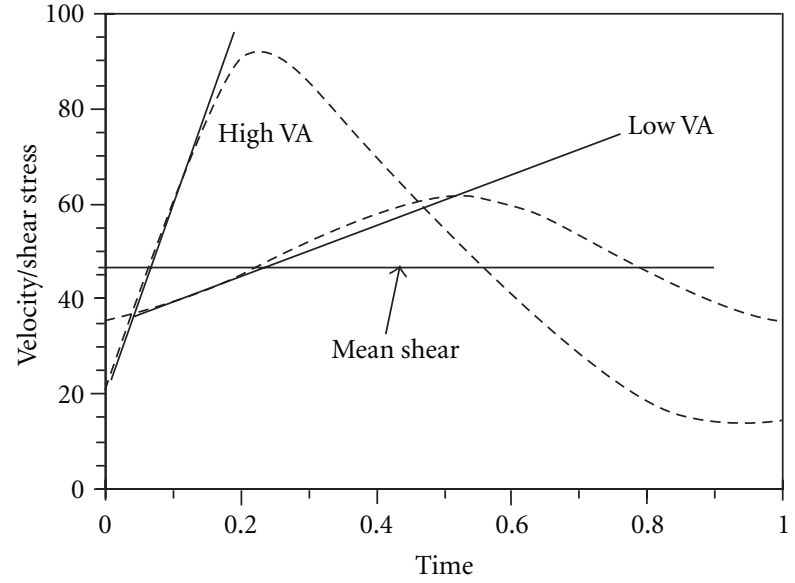

Figure 5: High versus Low Velocity Acceleration (VA). The horizontal line denotes identical mean shear stress for both VA rates.

in this initial compression wave travels distally into smaller arteries, some is reflected back towards the heart at sites of impedance mismatch. Interactions between forward- and backward-traveling waves result in complex blood flow patterns. Wave reflections result from arterial geometry, arterial wall compliance, and downstream resistance created by resistance arteries [57, 59].

Complex flow characteristics have a profound impact on the shear stress distribution to which vascular endothelial cells are exposed. While human in vivo studies typically describe shear stress as a mean construct, numerous secondary phenomena associated with flow, including pulsatile flow, retrograde flow, and flow turbulence, can influence the regulation of endothelial cells [23, 60, 62, 78-80].

6.1. Velocity Acceleration and Endothelial Function. The pulsatile nature of blood flow exposes the endothelial cells to two distinct shear stimuli during the cardiac cycle: a large rate of change in shear at the onset of flow (velocity acceleration), followed by a steady shear component (Figure 4). In vitro studies suggest that these two distinct fluid stimuli (velocity acceleration versus steady velocity) regulate short- and longterm endothelial function via independent biomechanical pathways [60-67]. For a given mean blood velocity, or shear stress, velocity acceleration can vary quite substantially (Figure 5). Studies have shown that the rate of velocity acceleration can affect the progression of atherosclerosis [60-62, 67, 81-85], endothelial cell function [62, 67, 86], mechanotransduction $[63-65,83,87]$, calcium kinetics [8891], and vascular tone [15-17, 92-94].

6.2. Velocity Acceleration and Flow-Mediated Dilation. The endothelium mediates flow-mediated vasodilation by altering the release of numerous factors, including $\mathrm{NO}, \mathrm{PGI}_{2}$ and EDHF factor. The development of sophisticated in vitro flow models has allowed the effects of velocity acceleration on cultured endothelial cell function to be studied. Notably, the release of $\mathrm{NO}$ and $\mathrm{PGI}_{2}$, from cultured endothelial cells has been directly related to the rate of velocity acceleration $[15,16,92,93]$. The rate of velocity acceleration has also been

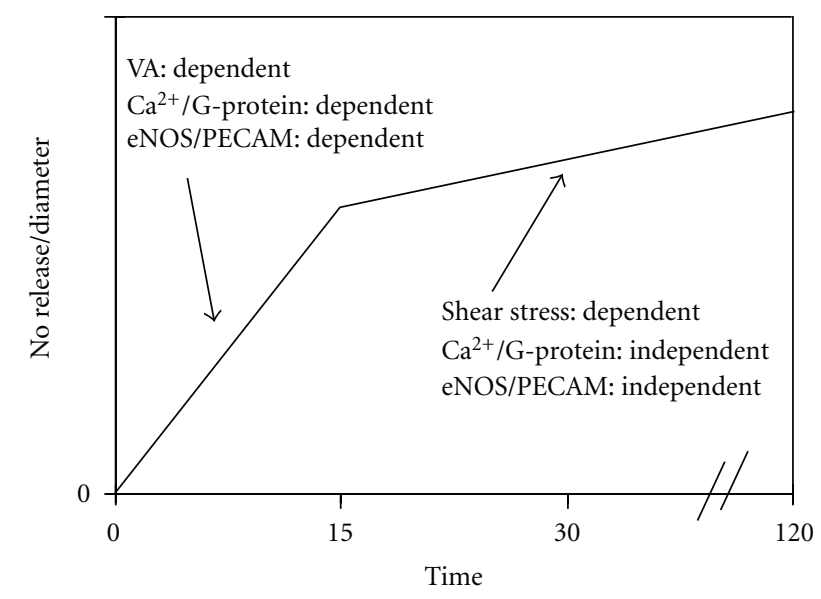

FIGure 6: Velocity Acceleration versus Shear Stress-Dependent Dilation. Velocity acceleration (VA) and mean shear stress appear to regulate nitric oxide production via distinct pathways. $\mathrm{Ca}^{+}$: calcium; eNOS: endothelial nitric oxide synthase; PECAM: platelet/endothelial cell adhesion molecule.

directly related to vasodilation of isolated cremaster arterioles [94].

The production rate of $\mathrm{NO}$ and $\mathrm{PGI}_{2}$ following flow onset exhibits a biphasic response, an initial transient burst followed by a slower release to a constant rate $[15,16,92]$. Separate studies from the same group $[15,16]$ demonstrated that the initial burst of NO is dependent on velocity acceleration but not the shear stress magnitude; the subsequent constant NO production is dependent on shear stress magnitude (Figure 6). The initial burst of $\mathrm{NO}$ was found to be $\mathrm{Ca}^{2+}$ and G-protein dependent (i.e., "localized" mechanotransduction). In contrast, the subsequent constant NO production was found to be $\mathrm{Ca}^{2+}$ and G-protein independent (i.e., "decentralized" mechanotransduction). A more recent study found that the initial velocity acceleration-dependent signal for NO release requires platelet/endothelial cell adhesion molecule-1 (PECAM-1) [17]. PECAM-1, which acts as an intracellular bridge between the two plasma membranes of neighboring cells, is complexed with endothelial nitric oxide synthase (eNOS) at the cell-cell junction. Velocity acceleration is thought to deform the endothelial cell plasma membrane and activate PCAM-1 [95]. The velocity accelerationdependent burst is consistent with previous in vitro observations $[96,97]$ for flow-mediated release of $\mathrm{PGI}_{2}$ and for the stimulation of $\mathrm{NO}$ release by $\mathrm{Ca}^{2+}$ mobilizing agonists [98]. Similar findings have been observed in isolated perfused vessels exposed to acute changes in flow $[41,94,99]$.

Recently, we studied the effect of velocity acceleration on FMD in a group of 14 healthy, young, male subjects [100]. FMD was measured prior to, and following, increases in velocity acceleration. Velocity acceleration was increased by inflating a tourniquet to $40 \mathrm{mmHg}$ around the forearm. We found a $14 \%$ increase in velocity acceleration-attenuated FMD by $11 \%$. This finding suggests that mean blood velocity alone may not adequately characterize the shear stimulus. Attention to secondary flow phenomena may be particularly 
important when comparing groups with known secondary flow abnormalities.

6.3. Potential Limitations of In Vitro Studies. The relevance of findings garnered from in vitro studies bear two important limitations. Firstly, endothelial cells from different tissue beds have been shown to exhibit different responses for a given flow paradigm [101]. For instance, it has been shown that different tissue beds exhibit different optimal flow frequencies for proliferation, eNOS activity, and $\mathrm{PGI}_{2}$ secretion [101]. Secondly, most culture studies have investigated endothelial gene regulation in response to a single type of stimulus (continuous laminar shear stress). Therefore, although these simple in vitro models have yielded valuable information, they fail to mimic the complexities of the in vivo environment. The applicability of these findings to humans remains to be determined.

\section{Velocity Acceleration and Vascular Health}

The effects of velocity acceleration on the development of atherosclerosis have produced conflicting findings. Bao et al. [60] found that velocity acceleration upregulated the expression of putative atherogenic genes (monocyte chemoattractant protein-1 and platelet-derived growth factor-A) which are believed to participate in the early events of atherosclerosis [102, 103]. The same group found that velocity acceleration upregulates endothelial cell proliferation [62]. However, a more recent study by Hsiai et al. [81] found that pulsatile flow actually downregulated the expression of monocyte chemoattractant protein-1 and reduced monocyte binding to lipid-oxidized endothelial cells. Furthermore, they found that the effects were more exaggerated for pulsatile flow with high velocity acceleration versus pulsatile flow with low velocity acceleration, even though mean shear stress was equivalent ( 50 dyne $/ \mathrm{cm}^{2}$ ).

Apart from the use of different endothelial cell cultures (bovine aortic [60] versus human umbilical [81]), a fundamental difference between the two aforementioned studies lies in the flow paradigms utilized. Bao et al. [60] evoked a single flow impulse (abrupt 0 to $16 \mathrm{dyne} / \mathrm{cm}^{2}$ sustained for 3 seconds), whereas Hsiai et al. [81] evoked pulsatile flow with a mean shear stress of 50 dyne $/ \mathrm{cm}^{2}$. Notably, the Hsiai et al. [81] flow model did not permit shear stress to return to zero between flow impulses, thereby, inducing a steady flow component. However, when Hsiai et al. [81] produced an oscillating flow profile $\left(0 \pm 5 \mathrm{dyne} / \mathrm{cm}^{2}\right)$, which induced high velocity acceleration but had a mean shear stress of 0 dyne $/ \mathrm{cm}^{2}$ and was devoid of a steady flow component, monocyte chemoattractant protein-1 expression was upregulated and monocyte binding was increased. This is consistent with the notion that, while endothelial cells derive directional cues from the flow direction or velocity, a certain persistence of the stimulus is required $[86,89]$. Taken together, these findings suggest that endothelial cells are regulated by a complex interplay between steady flow/shear stress and velocity acceleration.
In vivo, flow is pulsatile everywhere in the arterial system, but in most places there is a large steady component. However, at sites where flow oscillates with a low steady component, atherosclerotic lesions are known to occur. Again, this is consistent with the notion that while endothelial cells derive directional cues from the flow direction or velocity acceleration, a certain persistence of the stimulus is required $[86,89]$. Steady shear stress results in the continuous upregulation of antiatherogenic genes (manganese superoxide dismutase, cyclooxygenase-2, eNOS) [104]. Steady shear also promotes endothelial cell release of various bioactive substances that may be involved in the regulation of atherogenic genes, such as NO $[105,106]$. These findings suggest that the production of atherogenic genes by endothelial cells is regulated by the complex interaction between velocity acceleration and steady flow components.

7.1. Determinants of Velocity Acceleration. Velocity acceleration is altered by diseased states. Decreased velocity acceleration is seen with ventricular ischemia [107], acute myocardial infarction [108], and stenoses [109]; increased velocity acceleration occurs with hypertension [110], hyperthyroidism [111], bypass grafts [112], and obstruction of the lumen [113]. Velocity acceleration is also decreased by aging [110] and increased with physical activity [114-116] and vascular resistance $[110,117,118]$. Inadequate definition of the shear stimulus may hinder comparisons between the aforementioned patient groups, who exhibit differing rates of velocity acceleration even though mean blood velocities may be comparable. Therapies that affect velocity acceleration may also complicate longitudinal observations on patient groups.

\section{Calculating Shear Stress}

Future studies using the FMD test should consider both timeaveraged mean blood velocity and secondary flow parameters, particularly when making between-group comparisons. Emphasis is placed on the word consider since the FMD test should not be normalized to shear stress using conventional approaches. A number of studies have normalized the FMD response through dividing FMD by the shear stimulus or using an analysis of covariance (ANCOVA) approach [49, 119-123]. However, when using a General Linear Model (GLM), the following assumptions must hold true: (1) there must be at least a moderate correlation between the two variables (i.e., shear and FMD); (2) the relationship between shear and diameter must be linear; (3) the intercept for the regression slope must be zero; (4) variance must be similar between groups; (5) data must be normally distributed [121, 124]. A recent study found that that all assumptions for reliable use of shear-diameter ratios were violated [122].

The FMD response (i.e., change in diameter) can be normalized to the shear stimuli using hierarchical linear modeling (HLM) [125]. The advantage of HLM is that it allows the researcher to look at hierarchically structured data and interpret results without ignoring these structures. This is accomplished in HLM by including a complex random subject effect which can appropriately account for correlations among the data. This approach models different patterns of 
growth trajectories by allowing for the intercepts (initial diameter) and slopes (shear rate diameter) to randomly vary. A third level may also be specified: the specification of groups (e.g., to delineate differences in endothelial function) and/or the specification of an intervention or a modifiable risk factor such as smoking. This approach has previously been used to compare upper versus lower extremity arterial health in persons with spinal cord injury (SCI) [126], to assess improvements in arterial health following electrical stimulation-evoked resistance exercise therapy in persons with SCI [127], and to assess the effects of occasional cigarette smoking on arterial health [28]. The disadvantage of this approach is that multiple stimuli (preferably ranging from minimal to maximal shear stimuli) are required to generate a reliable shear-diameter slope; this results in lengthened testing time and potentially makes it more difficult to ascertain the mechanism(s) resulting in dilation.

\section{Conclusions}

Pulsatile flow, present throughout the arterial tree, results in endothelial cells being exposed to two distinct shear stimuli during the cardiac cycle: a large rate of change (velocity acceleration) in shear at the onset of flow, followed by relatively steady shear. In vitro studies suggest that these two distinct fluid stimuli (velocity acceleration versus steady shear) regulate short- and long-term endothelial function via independent biomechanical pathways. Studies have shown that the rate of velocity acceleration can affect mechanotransduction, vascular tone, and atherosclerosis. Velocity acceleration may be altered in a number of diseased states, as well as by aging and physical activity. Velocity acceleration may be an important independent variable governing the shear stimulus and should be considered when comparing groups with known secondary flow abnormalities.

\section{References}

[1] D. Lloyd-Jones, R. J. Adams, T. M. Brown et al., "Heart disease and stroke statistics8212;2010 update: a report from the American heart association," Circulation, vol. 121, no. 7, pp. e46-215, 2010.

[2] R. Ross, "The pathogenesis of atherosclerosis: a perspective for the 1990s," Nature, vol. 362, no. 6423, pp. 801-809, 1993.

[3] A. A. Quyyumi, "Prognostic value of endothelial function," American Journal of Cardiology, vol. 91, no. 12, pp. 19H-24H, 2003.

[4] J. N. Cohn, "Vascular wall function as a risk marker for cardiovascular disease," Journal of Hypertension, vol. 17, no. 5, pp. S41-S44, 1999.

[5] D. S. Celermajer, K. E. Sorensen, V. M. Gooch et al., "Noninvasive detection of endothelial dysfunction in children and adults at risk of atherosclerosis," Lancet, vol. 340, no. 8828, pp. 1111-1115, 1992.

[6] K. E. Pyke and M. E. Tschakovsky, "The relationship between shear stress and flow-mediated dilatation:implications for the assessment of endothelial function," Journal of Physiology, vol. 568, no. 2, pp. 357-369, 2005.

[7] G. F. Mitchell, H. Parise, J. A. Vita et al., "Local shear stress and brachial artery flow-mediated dilation: the Framingham heart study," Hypertension, vol. 44, no. 2, pp. 134-139, 2004.
[8] B. A. Parker, T. L. Trehearn, and J. R. Meendering, "Pick your Poiseuille: normalizing the shear stimulus in studies of flowmediated dilation," Journal of Applied Physiology, vol. 107, no. 4, pp. 1357-1359, 2009.

[9] L. Stoner and K. McCully, Blood Velocity Parameters that Contibute to Flow-Mediated Dilation, LAP LAMBERT Academic, Saarbrücken, Germany, 2011.

[10] A. Koller, D. Sun, and G. Kaley, "Role of shear stress and endothelial prostaglandins in flow- and viscosity-induced dilation of arterioles in vitro," Circulation Research, vol. 72, no. 6, pp. 1276-1284, 1993.

[11] S. K. Samijo, J. M. Willigers, P. J. Brands et al., "Reproducibility of shear rate and shear stress assessment by means of ultrasound in the common carotid artery of young human males and females," Ultrasound in Medicine and Biology, vol. 23, no. 4, pp. 583-590, 1997.

[12] S. Oyre, E. M. Pedersen, S. Ringgaard, P. Boesiger, and W. P. Paaske, "In vivo wall shear stress measured by magnetic resonance velocity mapping in the normal human abdominal aorta," European Journal of Vascular and Endovascular Surgery, vol. 13, no. 3, pp. 263-271, 1997.

[13] R. S. Reneman, T. Arts, and A. P. G. Hoeks, "Wall shear stress-an important determinant of endothelial cell function and structure-in the arterial system in vivo," Journal of Vascular Research, vol. 43, no. 3, pp. 251-269, 2006.

[14] P. D. Gatehouse, J. Keegan, L. A. Crowe et al., "Applications of phase-contrast flow and velocity imaging in cardiovascular MRI," European Radiology, vol. 15, no. 10, pp. 2172-2184, 2005.

[15] M. J. Kuchan, H. Jo, and J. A. Frangos, "Role of G proteins in shear stress-mediated nitric oxide production by endothelial cells," American Journal of Physiology, vol. 267, no. 3, pp. C753-C758, 1994.

[16] J. A. Frangos, T. Y. Huang, and C. B. Clark, "Steady shear and step changes in shear stimulate endothelium via independent mechanisms superposition of transient and sustained nitric oxide production," Biochemical and Biophysical Research Communications, vol. 224, no. 3, pp. 660-665, 1996.

[17] N. Dusserre, N. L'Heureux, K. S. Bell et al., "PECAM-1 interacts with nitric oxide synthase in human endothelial cells: implication for flow-induced nitric oxide synthase activation," Arteriosclerosis, Thrombosis, and Vascular Biology, vol. 24, no. 10, pp. 1796-1802, 2004.

[18] A. Peretz, D. F. Leotta, J. H. Sullivan et al., "Flow mediated dilation of the brachial artery: an investigation of methods requiring further standardization," BMC Cardiovascular Disorders, vol. 7, article 11, 2007.

[19] M. C. Corretti, T. J. Anderson, E. J. Benjamin et al., "Guidelines for the ultrasound assessment of endothelial-dependent flow-mediated vasodilation of the brachial artery: a report of the international brachial artery reactivity task force," Journal of the American College of Cardiology, vol. 39, no. 2, pp. 257265, 2002.

[20] R. A. Harris, S. K. Nishiyama, D. W. Wray, and R. S. Richardson, "Ultrasound assessment of flow-mediated dilation," $\mathrm{Hy}$ pertension, vol. 55, no. 5, pp. 1075-1085, 2010.

[21] D. H. Thijssen, M. A. Black, K. E. Pyke et al., "Assessment of flow-mediated dilation in humans: a methodological and physiological guideline," American Journal of Physiology: Heart and Circulatory Physiology, vol. 300, no. 1, pp. H2-H12, 2011.

[22] D. S. Celermajer, K. E. Sorensen, C. Bull, J. Robinson, and J. E. Deanfield, "Endothelium-dependent dilation in the systemic arteries of asymptomatic subjects relates to coronary risk 
factors and their interaction," Journal of the American College of Cardiology, vol. 24, no. 6, pp. 1468-1474, 1994.

[23] T. M. Tinken, D. H. J. Thijssen, N. Hopkins et al., "Impact of shear rate modulation on vascular function in humans," Hypertension, vol. 54, no. 2, pp. 278-285, 2009.

[24] G. Chironi, D. Craiem, J. Miranda-Lacet, J. Levenson, and A. Simon, "Impact of shear stimulus, risk factor burden and early atherosclerosis on the time-course of brachial artery flow-mediated vasodilation," Journal of Hypertension, vol. 26, no. 3, pp. 508-515, 2008.

[25] R. S. Reneman, T. Arts, and A. P. Hoeks, "Wall shear stressan important determinant of endothelial cell function and structure-in the arterial system in vivo: discrepancies with theory," Journal of Vascular Research, vol. 43, no. 3, pp. 251269, 2006.

[26] H. A. Silber, P. Ouyang, D. A. Bluemke, S. N. Gupta, T. K. Foo, and J. A. C. Lima, "Why is flow-mediated dilation dependent on arterial size? Assessment of the shear stimulus using phase-contrast magnetic resonance imaging," American Journal of Physiology: Heart and Circulatory Physiology, vol. 288, no. 2, pp. H822-H828, 2005.

[27] L. Stoner, M. Sabatier, K. Edge, and K. McCully, "Relationship between blood velocity and conduit artery diameter and the effects of smoking on vascular responsiveness," Journal of Applied Physiology, vol. 96, no. 6, pp. 2139-2145, 2004.

[28] L. Stoner, M. J. Sabatier, C. D. Black, and K. K. McCully, "Occasional cigarette smoking chronically affects arterial function," Ultrasound in Medicine and Biology, vol. 34, no. 12, pp. 1885-1892, 2008.

[29] A. I. Barakat, "Responsiveness of vascular endothelium to shear stress: potential role of ion channels and cellular cytoskeleton (review)," International Journal of Molecular Medicine, vol. 4, no. 4, pp. 323-332, 1999.

[30] P. F. Davies, "Flow-mediated endothelial mechanotransduction," Physiological Reviews, vol. 75, no. 3, pp. 519-560, 1995.

[31] A. B. Fisher, S. Chien, A. I. Barakat, and R. M. Nerem, "Endothelial cellular response to altered shear stress," American Journal of Physiology: Lung Cellular and Molecular Physiology, vol. 281, no. 3, pp. L529-L533, 2001.

[32] I. Fleming and R. Busse, "Molecular mechanisms involved in the regulation of the endothelial nitric oxide synthase," American Journal of Physiology: Regulatory Integrative and Comparative Physiology, vol. 284, no. 1, pp. R1-R12, 2003.

[33] V. Labrador, K. D. Chen, Y. S. Li, S. Muller, J. F. Stoltz, and S. Chien, "Interactions of mechanotransduction pathways," Biorheology, vol. 40, no. 1-3, pp. 47-52, 2002.

[34] J. Y. J. Shyy and S. Chien, "Role of integrins in endothelial mechanosensing of shear stress," Circulation Research, vol. 91, no. 9, pp. 769-775, 2002.

[35] S. P. Olesen, D. E. Claphamt, and P. F. Davies, "Haemodynamic shear stress activates a $\mathrm{K}+$ current in vascular endothelial cells," Nature, vol. 331, no. 6152, pp. 168-170, 1988.

[36] E. R. Jacobs, C. Cheliakine, D. Gebremedhin, E. K. Birks, P. F. Davies, and D. R. Harder, "Shear activated channels in cellattached patches of cultured bovine aortic endothelial cells," Pflügers Archiv, vol. 431, no. 1, pp. 129-131, 1995.

[37] A. I. Barakat, E. V. Leaver, P. A. Pappone, and P. F. Davies, "A flow-activated chloride-selective membrane current in vascular endothelial cells," Circulation Research, vol. 85, no. 9, pp. 820-828, 1999.

[38] M. Nakao, K. Ono, S. Fujisawa, and T. Iijima, "Mechanical stress-induced $\mathrm{Ca}^{2+}$ entry and $\mathrm{Cl}$ - current in cultured human aortic endothelial cells," American Journal of Physiology, vol. 276, no. 1, pp. C238-C249, 1999.
[39] B. L. Langille and F. O’Donnell, "Reductions in arterial diameter produced by chronic decreases in blood flow are endothelium-dependent," Science, vol. 231, no. 4736, pp. 405-407, 1986.

[40] I. Fleming and R. Busse, "Molecular mechanisms involved in the regulation of the endothelial nitric oxide synthase," American Journal of Physiology-Regulatory Integrative and Comparative Physiology, vol. 284, no. 1, pp. R1-R12, 2003.

[41] J. P. Cooke, E. Rossitch, N. A. Andon, J. Loscalzo, and V. J. Dzau, "Flow activates an endothelial potassium channel to release an endogenous nitrovasodilator," Journal of Clinical Investigation, vol. 88, no. 5, pp. 1663-1671, 1991.

[42] A. M. Malek and S. Izumo, "Molecular aspects of signal transduction of shear stress in the endothelial cell," Journal of Hypertension, vol. 12, no. 9, pp. 989-999, 1994.

[43] J. Suvatne, A. I. Barakat, and M. E. O'Donnell, "Flowinduced expression of endothelial $\mathrm{Na}-\mathrm{K}-\mathrm{Cl}$ cotransport: dependence on $\mathrm{K}+$ and Cl- channels," American Journal of Physiology, vol. 280, no. 1, pp. C216-C227, 2001.

[44] B. P. Helmke and P. F. Davies, "The cytoskeleton under external fluid mechanical forces: hemodynamic forces acting on the endothelium," Annals of Biomedical Engineering, vol. 30, no. 3, pp. 284-296, 2002.

[45] N. Wang, J. P. Butler, and D. E. Ingber, "Mechanotransduction across the cell surface and through the cytoskeleton," Science, vol. 260, no. 5111, pp. 1124-1127, 1993.

[46] S. Chien, S. Usami, H. M. Taylor, J. L. Lundberg, and M. I. Gregersen, "Effects of hematocrit and plasma proteins on human blood rheology at low shear rates," Journal of Applied Physiology, vol. 21, no. 1, pp. 81-87, 1966.

[47] D. D. Duncan, C. B. Bargeron, S. E. Borchardt et al., "The effect of compliance on wall shear in casts of a human aortic bifurcation," Journal of Biomechanical Engineering, vol. 112, no. 2, pp. 183-188, 1990.

[48] G. J. Tangelder, H. C. Teirlinck, D. W. Slaaf, and R. S. Reneman, "Distribution of blood platelets flowing in arterioles," American Journal of Physiology: Heart and Circulatory Physiology, vol. 248, no. 3, pp. H318-323, 1985.

[49] J. Padilla, B. D. Johnson, S. C. Newcomer et al., "Normalization of flow-mediated dilation to shear stress area under the curve eliminates the impact of variable hyperemic stimulus," Cardiovascular Ultrasound, vol. 6, article 44, 2008.

[50] A. Gnasso, C. Carallo, C. Irace et al., "Association between intima-media thickness and wall shear stress in common carotid arteries in healthy male subjects," Circulation, vol. 94, no. 12, pp. 3257-3262, 1996.

[51] R. Joannides, E. H. Bakkali, V. Richard, A. Benoist, N. Moore, and C. Thuillez, "Evaluation of the determinants of flowmediated radial artery vasodilatation in humans," Clinical and Experimental Hypertension, vol. 19, no. 5-6, pp. 813-826, 1997.

[52] A. C. Betik, V. B. Luckham, and R. L. Hughson, "Flow-mediated dilation in human brachial artery after different circulatory occlusion conditions," American Journal of Physiology: Heart and Circulatory Physiology, vol. 286, no. 1, pp. H442H448, 2004.

[53] K. E. Pyke, E. M. Dwyer, and M. E. Tschakovsky, "Impact of controlling shear rate on flow-mediated dilation responses in the brachial artery of humans," Journal of Applied Physiology, vol. 97, no. 2, pp. 499-508, 2004.

[54] B. Y. Salazar Vázquez, J. Martini, A. Chávez Negrete et al., "Cardiovascular benefits in moderate increases of blood and plasma viscosity surpass those associated with lowering viscosity: experimental and clinical evidence," Clinical 
Hemorheology and Microcirculation, vol. 44, no. 2, pp. 75-85, 2010.

[55] R. Dammers, F. Stifft, J. H. M. Tordoir, J. M. M. Hameleers, A. P. G. Hoeks, and P. J. E. H. M. Kitslaar, "Shear stress depends on vascular territory: comparison between common carotid and brachial artery," Journal of Applied Physiology, vol. 94, no. 2, pp. 485-489, 2003.

[56] L. Stoner, J. M. Young, and M. J. Sabatier, "Examination of possible flow turbulence during flow-mediated dilation testing," Open Journal of Medical Imaging, vol. 1, no. 1, pp. 1-8, 2011.

[57] A. Barakat and D. Lieu, "Differential responsiveness of vascular endothelial cells to different types of fluid mechanical shear stress," Cell Biochemistry and Biophysics, vol. 38, no. 3, pp. 323-343, 2003.

[58] K. Perktold and G. Rappitsch, "Computer simulation of local blood flow and vessel mechanics in a compliant carotid artery bifurcation model," Journal of Biomechanics, vol. 28, no. 7, pp. 845-856, 1995.

[59] K. Perktold and G. Rappitsch, "Mathematical modeling of arterial blood flow and correlation to atherosclerosis," Technology and Health Care, vol. 3, no. 3, pp. 139-151, 1995.

[60] X. Bao, C. Lu, and J. A. Frangos, "Temporal gradient in shear but not steady shear stress induces PDGF-A and MCP-1 expression in endothelial eells : role of NO, NF $\kappa \mathrm{B}$, and egr-1," Arteriosclerosis, Thrombosis, and Vascular Biology, vol. 19, no. 4, pp. 996-1003, 1999.

[61] M. Ojha, "Wall shear stress temporal gradient and anastomotic intimal hyperplasia," Circulation Research, vol. 74, no. 6, pp. 1227-1231, 1994.

[62] C. R. White, M. Haidekker, X. Bao, and J. A. Frangos, “Temporal gradients in shear, but not spatial gradients, stimulate endothelial cell proliferation," Circulation, vol. 103, no. 20, pp. 2508-2513, 2001.

[63] C. R. White, H. Y. Stevens, M. Haidekker, and J. A. Frangos, "Temporal gradients in shear, but not spatial gradients, stimulate ERK1/2 activation in human endothelial cells," American Journal of Physiology: Heart and Circulatory Physiology, vol. 289, no. 6, pp. H2350-H2355, 2005.

[64] X. Bao, C. Lu, and J. A. Francos, "Mechanism of temporal gradients in shear-induced ERK1/2 activation and proliferation in endothelial cells," American Journal of Physiology: Heart and Circulatory Physiology, vol. 281, no. 1, pp. H22H29, 2001.

[65] X. Bao, C. B. Clark, and J. A. Frangos, "Temporal gradient in shear-induced signaling pathway: involvement of MAP kinase, c-fos, and connexin43," American Journal of Physiology: Heart and Circulatory Physiology, vol. 278, no. 5, pp. H1598-H1605, 2000.

[66] B. R. Blackman, G. García-Cardeña, and M. A. Gimbrone Jr., "A new in vitro model to evaluate differential responses of endothelial cells to simulated arterial shear stress waveforms," Journal of Biomechanical Engineering, vol. 124, no. 4, pp. 397407, 2002.

[67] T. K. Hsiai, S. K. Cho, H. M. Honda et al., "Endothelial cell dynamics under pulsating flows: significance of high versus low shear stress slew rates (d(tau)/dt)," Annals of Biomedical Engineering, vol. 30, no. 5, pp. 646-656, 2002.

[68] P. F. Davies, A. Remuzzi, and E. J. Gordon, “Turbulent fluid shear stress induces vascular endothelial cell turnover in vitro," Proceedings of the National Academy of Sciences of the United States of America, vol. 83, no. 7, pp. 2114-2117, 1986.
[69] G. Helmlinger, R. V. Geiger, S. Schreck, and R. M. Nerem, "Effects of pulsatile flow on cultured vascular endothelial cell morphology," Journal of Biomechanical Engineering, vol. 113, no. 2, pp. 123-131, 1991.

[70] C. M. Waters, J. Y. Chang, M. R. Glucksberg, N. DePaola, and J. B. Grotberg, "Mechanical forces alter growth factor release by pleural mesothelial cells," American Journal of Physiology, vol. 272, no. 3, pp. L552-L557, 1997.

[71] T. N. McAllister, T. Du, and J. A. Frangos, "Fluid shear stress stimulates prostaglandin and nitric oxide release in bone marrow-derived preosteoclast-like cells," Biochemical and Biophysical Research Communications, vol. 270, no. 2, pp. 643-648, 2000.

[72] X. Peng, F. A. Recchia, B. J. Byrne, I. S. Wittstein, R. C. Ziegelstein, and D. A. Kass, "In vitro system to study realistic pulsatile flow and stretch signaling in cultured vascular cells," American Journal of Physiology, vol. 279, no. 3, pp. C797C805, 2000.

[73] R. M. Lum, L. M. Wiley, and A. I. Barakat, "Influence of different forms of fluid shear stress on vascular endothelial TGF- $\beta 1$ mRNA expression," International Journal of Molecular Medicine, vol. 5, no. 6, pp. 635-641, 2000.

[74] G. Apodaca, "Modulation of membrane traffic by mechanical stimuli," American Journal of Physiology: Renal Physiology, vol. 282, no. 2, pp. F179-F190, 2002.

[75] J. P. Cullen, S. Sayeed, R. S. Sawai et al., "Pulsatile flowinduced angiogenesis: role of Gi subunits," Arteriosclerosis, Thrombosis, and Vascular Biology, vol. 22, no. 10, pp. 16101616, 2002.

[76] D. M. Wootton and D. N. Ku, "Fluid mechanics of vascular systems, diseases, and thrombosis," Annual Review of Biomedical Engineering, vol. 1, no. 1, pp. 299-329, 1999.

[77] J. J. Wang and K. H. Parker, "Wave propagation in a model of the arterial circulation," Journal of Biomechanics, vol. 37, no. 4, pp. 457-470, 2004.

[78] D. H. Thijssen, E. A. Dawson, T. M. Tinken, N. T. Cable, and D. J. Green, "Retrograde flow and shear rate acutely impair endothelial function in humans," Hypertension, vol. 53, no. 6, pp. 986-992, 2009.

[79] Y. Hoi et al., "Correlation between local hemodynamics and lesion distribution in a novel aortic regurgitation murine model of atherosclerosis," Annals of Biomedical Engineering, vol. 39, no. 5, pp. 1414-1422, 2011.

[80] J.-J. Chiu and S. Chien, "Effects of disturbed flow on vascular endothelium: pathophysiological basis and clinical perspectives," Physiological Reviews, vol. 91, no. 1, pp. 327-387, 2011.

[81] T. K. Hsiai, S. K. Cho, S. Reddy et al., "Pulsatile flow regulates monocyte adhesion to oxidized lipid-induced endothelial cells," Arteriosclerosis, Thrombosis, and Vascular Biology, vol. 21, no. 11, pp. 1770-1776, 2001.

[82] T. K. Hsiai, S. K. Cho, P. K. Wong et al., "Monocyte recruitment to endothelial cells in response to oscillatory shear stress," FASEB Journal, vol. 17, no. 12, pp. 1648-1657, 2003.

[83] H. J. Hsieh, N. Q. Li, and J. A. Frangos, "Pulsatile and steady flow induces c-fos expression in human endothelial cells," Journal of Cellular Physiology, vol. 154, no. 1, pp. 143-151, 1993.

[84] N. DePaola, M. A. Gimbrone, P. F. Davies, and C. F. Dewey, "Vascular endothelium responds to fluid shear stress gradients," Arteriosclerosis and Thrombosis, vol. 12, no. 11, pp. 1254-1257, 1993.

[85] J. Strony, A. Beaudoin, D. Brands, and B. Adelman, "Analysis of shear stress and hemodynamic factors in a model of coronary artery stenosis and thrombosis," American Journal of 
Physiology: Heart and Circulatory Physiology, vol. 265, no. 5, pp. H1787-H1796, 1993.

[86] P. F. Davies, C. F. Dewey, and S. R. Bussolari, "Influence of hemodynamic forces on vascular endothelial function. In vitro studies of shear stress and pinocytosis in bovine aortic cells," Journal of Clinical Investigation, vol. 73, no. 4, pp. 1121-1129, 1984.

[87] P. J. Butler, T. C. Tsou, J. Y. Li, S. Usami, and S. Chien, "Rate sensitivity of shear-induced changes in the lateral diffusion of endothelial cell membrane lipids: a role for membrane perturbation in shear-induced MAPK activation," The FASEB Journal, vol. 16, no. 2, pp. 216-218, 2002.

[88] G. Helmlinger, B. C. Berk, and R. M. Nerem, "Calcium responses of endothelial cell monolayers subjected to pulsatile and steady laminar flow differ," American Journal of Physiology, vol. 269, no. 2, pp. C367-C375, 1995.

[89] G. Helmlinger, B. C. Berk, and R. M. Nerem, "Pulsatile and steady flow-induced calcium oscillations in single cultured endothelial cells," Journal of Vascular Research, vol. 33, no. 5, pp. 360-369, 1996.

[90] B. R. Blackman, K. A. Barbee, and L. E. Thibault, "In vitro cell shearing device to investigate the dynamic response of cells in a controlled hydrodynamic environment," Annals of Biomedical Engineering, vol. 28, no. 4, pp. 363-372, 2000.

[91] B. R. Blackman, L. E. Thibault, and K. A. Barbee, "Selective modulation of endothelial cell $\mathrm{Ca}^{2+}$ response to flow by the onset rate of shear stress," Journal of Biomechanical Engineering, vol. 122, no. 3, pp. 274-282, 2000.

[92] J. A. Frangos, S. G. Eskin, L. V. McIntire, and C. L. Ives, "Flow effects on prostacyclin production by cultured human endothelial cells," Science, vol. 227, no. 4693, pp. 1477-1479, 1985.

[93] M. Noris, M. Morigi, R. Donadelli et al., "Nitric oxide synthesis by cultured endothelial cells is modulated by flow conditions," Circulation Research, vol. 76, no. 4, pp. 536-543, 1995.

[94] P. J. Butler, S. Weinbaum, S. Chien, and D. E. Lemons, "Endothelium-dependent, shear-induced vasodilation is rate-sensitive," Microcirculation, vol. 7, no. 1, pp. 53-65, 2000.

[95] M. W. Klymkowsky and B. Parr, "The body language of cells: the intimate connection between cell adhesion and behavior," Cell, vol. 83, no. 1, pp. 5-8, 1995.

[96] F. Berthiaume and J. A. Frangos, "Flow-induced prostacyclin production is mediated by a pertussis toxin-sensitive $\mathrm{G}$ protein," FEBS Letters, vol. 308, no. 3, pp. 277-279, 1992.

[97] E. F. Grabowski, E. A. Jaffe, and B. B. Weksler, "Prostacyclin production by cultured endothelial cell monolayers exposed to step increases in shear stress," Journal of Laboratory and Clinical Medicine, vol. 105, no. 1, pp. 36-43, 1985.

[98] A. Luckhoff, U. Pohl, A. Mulsch, and R. Busse, "Differential role of extra- and intracellular calcium in the release of EDRF and prostacyclin from cultured endothelial cells," British Journal of Pharmacology, vol. 95, no. 1, pp. 189-196, 1988.

[99] G. M. Rubanyi, A. D. Freay, K. Kauser, A. Johns, and D. R. Harder, "Mechanoreception by the endothelium: mediators and mechanisms of pressure- and flow-induced vascular responses," Blood Vessels, vol. 27, no. 2-5, pp. 246-257, 1990.

[100] L. Stoner and K. McCully, "Velocity acceleration as a determinant of flow-mediated dilation," Ultrasound in Medicine and Biology. In press.

[101] M. Balcells et al., "Cells in fluidic environments are sensitive to flow frequency," Journal of Cellular Physiology, vol. 204, no. 1, pp. 329-335, 2005.
[102] S. D. Cushing, J. A. Berliner, A. J. Valente et al., "Minimally modified low density lipoprotein induces monocyte chemotactic protein 1 in human endothelial cells and smooth muscle cells," Proceedings of the National Academy of Sciences of the United States of America, vol. 87, no. 13, pp. 5134-5138, 1990.

[103] J. N. Wilcox, K. M. Smith, L. T. Williams, S. M. Schwartz, and D. Gordon, "Platelet-derived growth factor mRNA detection in human atherosclerotic plaques by in situ hybridization," Journal of Clinical Investigation, vol. 82, no. 3, pp. 1134-1143, 1988.

[104] J. N. Topper, J. Cai, D. Falb, and M. A. Gimbrone, "Identification of vascular endothelial genes differentially responsive to fluid mechanical stimuli: cyclooxygenase-2, manganese superoxide dismutase, and endothelial cell nitric oxide synthase are selectively up-regulated by steady laminar shear stress," Proceedings of the National Academy of Sciences of the United States of America, vol. 93, no. 19, pp. 10417-10422, 1996.

[105] M. J. Kuchan and J. A. Frangos, "Role of calcium and calmodulin in flow-induced nitric oxide production in endothelial cells," American Journal of Physiology, vol. 266, no. 3, pp. C628-C636, 1994.

[106] S. Moncada and E. A. Higgs, "Endogenous nitric oxide: physiology, pathology and clinical relevance," European Journal of Clinical Investigation, vol. 21, no. 4, pp. 361-374, 1991.

[107] H. N. Sabbah, J. Przybylski, D. E. Albert, and P. D. Stein, "Peak aortic blood acceleration reflects the extent of left ventricular ischemic mass at risk," American Heart Journal, vol. 113, no. 4, pp. 885-890, 1987.

[108] P. Kezdi, E. L. Stanley, W. J. Marshall, and R. K. Kordenat, "Aortic flow velocity and acceleration as an index of ventricular performance during myocardial infarction," American Journal of the Medical Sciences, vol. 257, no. 1, pp. 61-71, 1969.

[109] M. Bassini, E. Gatti, and T. Longo, "In vivo recording of blood velocity profiles and studies in vitro of profile alterations induced by known stenoses," Texas Heart Institute Journal, vol. 9, no. 2, pp. 185-194, 1982.

[110] A. Sainz, J. Cabau, and V. C. Roberts, "Deceleration vs. acceleration: a haemodynamic parameter in the assessment of vascular reactivity. A preliminary study," Medical Engineering and Physics, vol. 17, no. 2, pp. 91-95, 1995.

[111] D. Chemla, J. Levenson, P. Valensi et al., "Effect of beta adrenoceptors and thyroid hormones on velocity and acceleration of peripheral arterial flow in hyperthyroidism," American Journal of Cardiology, vol. 65, no. 7, pp. 494-500, 1990.

[112] G. Baccelli, P. Pignoli, and E. Corbellini, "Hemodynamic factors changing blood flow velocity waveform and profile in normal human brachial artery," Angiology, vol. 36, no. 1, pp. $1-8,1985$.

[113] A. Mailhac, J. J. Badimon, J. T. Fallon et al., "Effect of an eccentric severe stenosis on fibrin(ogen) deposition on severely damaged vessel wall in arterial thrombosis: relative contribution of fibrin(ogen) and platelets," Circulation, vol. 90, no. 2, pp. 988-996, 1994.

[114] M. Shechter, S. Matetzky, M. S. Feinberg, P. Chouraqui, Z. Rotstein, and H. Hod, "External counterpulsation therapy improves endothelial function in patients with refractory angina pectoris," Journal of the American College of Cardiology, vol. 42, no. 12, pp. 2090-2095, 2003.

[115] P. O. Bonetti, G. W. Barsness, P. C. Keelan et al., "Enhanced external counterpulsation improves endothelial function in patients with symptomatic coronary artery disease," Journal 
of the American College of Cardiology, vol. 41, no. 10, pp. 1761-1768, 2003.

[116] E. M. Pedersen, M. Agerbaek, I. B. Kristensen, and A. P. Yoganathan, "Wall shear stress and early atherosclerotic lesions in the abdominal aorta in young adults," European Journal of Vascular and Endovascular Surgery, vol. 13, no. 5, pp. 443-451, 1997.

[117] B. J. Sjoberg, L. Eidenvall, D. Loyd, B. Wranne, and P. Ask, "Vascular characteristics influence the aortic ultrasound Doppler signal: computer and hydraulic model simulations," Acta Physiologica Scandinavica, vol. 147, no. 3, pp. 271-279, 1993.

[118] K. E. Crutchfield, A. Y. Razumovsky, C. H. Tegeler, and B. R. Mozayeni, "Differentiating vascular pathophysiological states by objective analysis of flow dynamics," Journal of Neuroimaging, vol. 14, no. 2, pp. 97-107, 2004.

[119] B. A. Parker, S. J. Ridout, and D. N. Proctor, "Age and flowmediated dilation: a comparison of dilatory responsiveness in the brachial and popliteal arteries," American Journal of Physiology: Heart and Circulatory Physiology, vol. 291, no. 6, pp. H3043-H3049, 2006.

[120] K. E. Pyke and F. Jazuli, "Impact of repeated increases in shear stress via reactive hyperemia and handgrip exercise: no evidence of systematic changes in brachial artery FMD," American Journal of Physiology: Heart and Circulatory Physiology, vol. 300, no. 3, pp. H1078-H1089, 2011.

[121] G. Atkinson, A. M. Batterham, M. A. Black et al., "Is the ratio of flow-mediated dilation and shear rate a statistically sound approach to normalization in cross-sectional studies on endothelial function?" Journal of Applied Physiology, vol. 107, no. 6, pp. 1893-1899, 2009.

[122] D. H. Thijssen, L. M. Bullens, M. M. Van Bemmel et al., "Does arterial shear explain the magnitude of flow-mediated dilation?: a comparison between young and older humans," American Journal of Physiology: Heart and Circulatory Physiology, vol. 296, no. 1, pp. H57-H64, 2009.

[123] P. C. de Groot, F. Poelkens, M. Kooijman, and M. T. E. Hopman, "Preserved flow-mediated dilation in the inactive legs of spinal cord-injured individuals," American Journal of Physiology: Heart and Circulatory Physiology, vol. 287, no. 1, pp. H374-H380, 2004.

[124] D. B. Allison, F. Paultre, M. I. Goran, E. T. Poehlman, and S. B. Heymsfield, "Statistical considerations regarding the use of ratios to adjust data," International Journal of Obesity and Related Metabolic Disorders Journal, vol. 19, no. 9, pp. 644652, 1995.

[125] S. W. Raudenbush and A. S. Bryk, Hierarchical Linear Models: Applications and Data Analysis Methods (Advanced Quantitative Techniques in the Social Sciences), Sage, Thousand Oaks, Calif, USA, 2001.

[126] L. Stoner, M. Sabatier, L. VanhHiel et al., "Upper vs lower extremity arterial function after spinal cord injury," Journal of Spinal Cord Medicine, vol. 29, no. 2, pp. 138-146, 2006.

[127] L. Stoner, M. J. Sabatier, E. T. Mahoney, G. A. Dudley, and K. K. McCully, "Electrical stimulation-evoked resistance exercise therapy improves arterial health after chronic spinal cord injury," Spinal Cord, vol. 45, no. 1, pp. 49-56, 2007. 


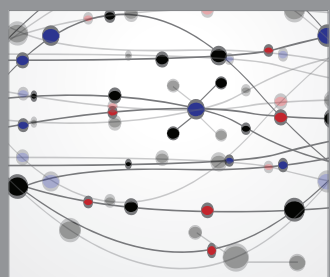

The Scientific World Journal
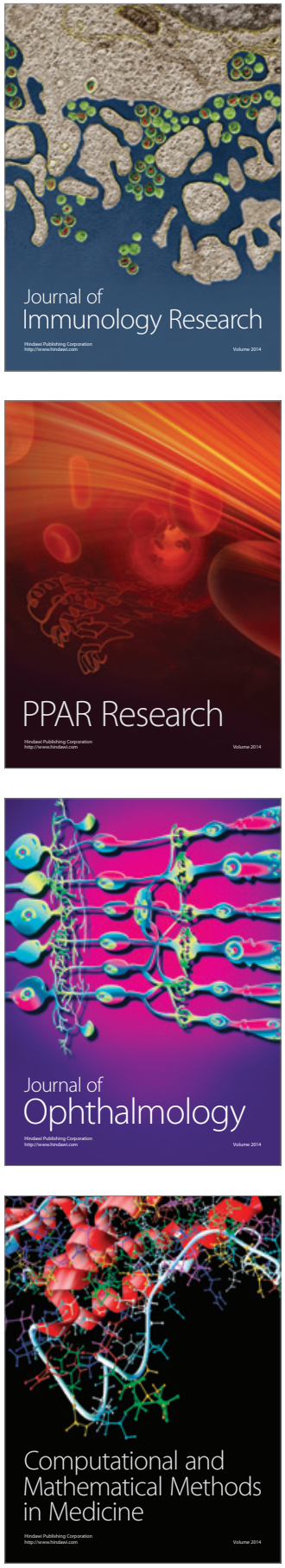

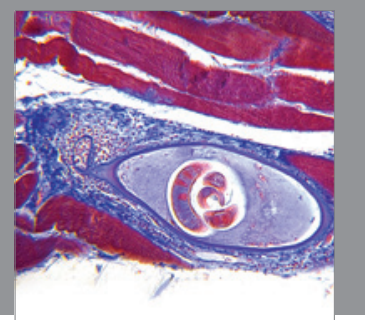

Gastroenterology

Research and Practice
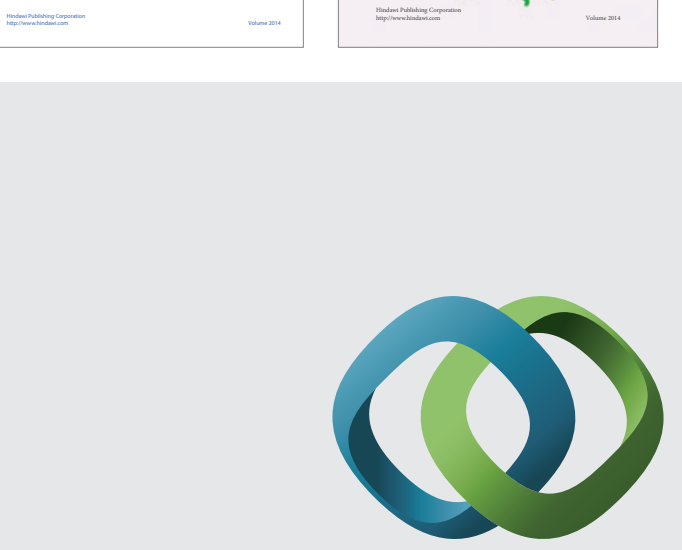

\section{Hindawi}

Submit your manuscripts at

http://www.hindawi.com
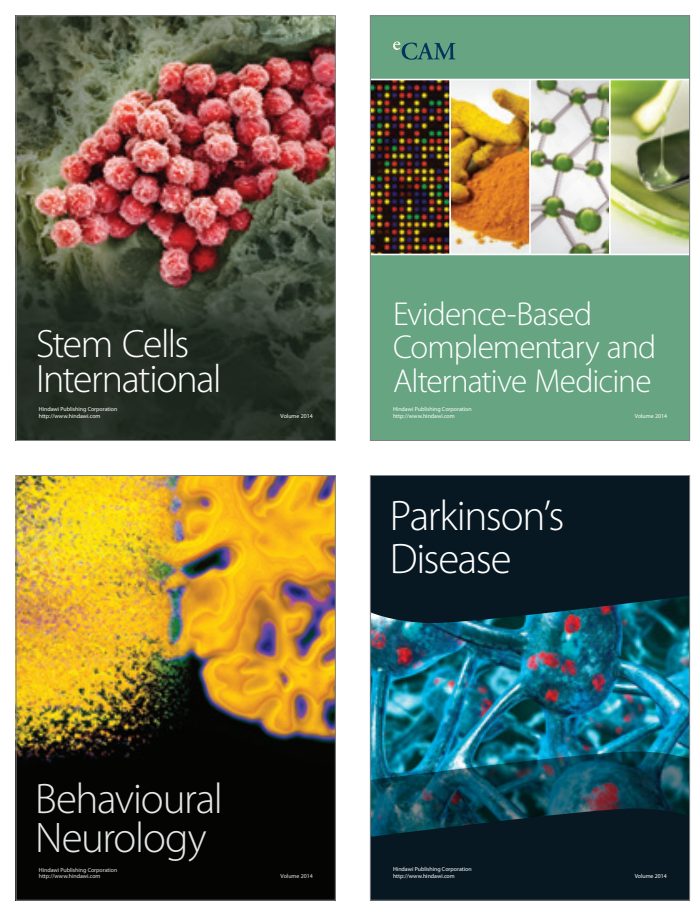

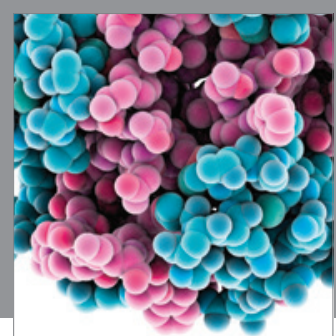

Journal of
Diabetes Research

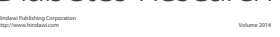

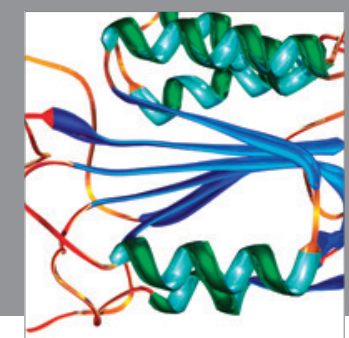

Disease Markers
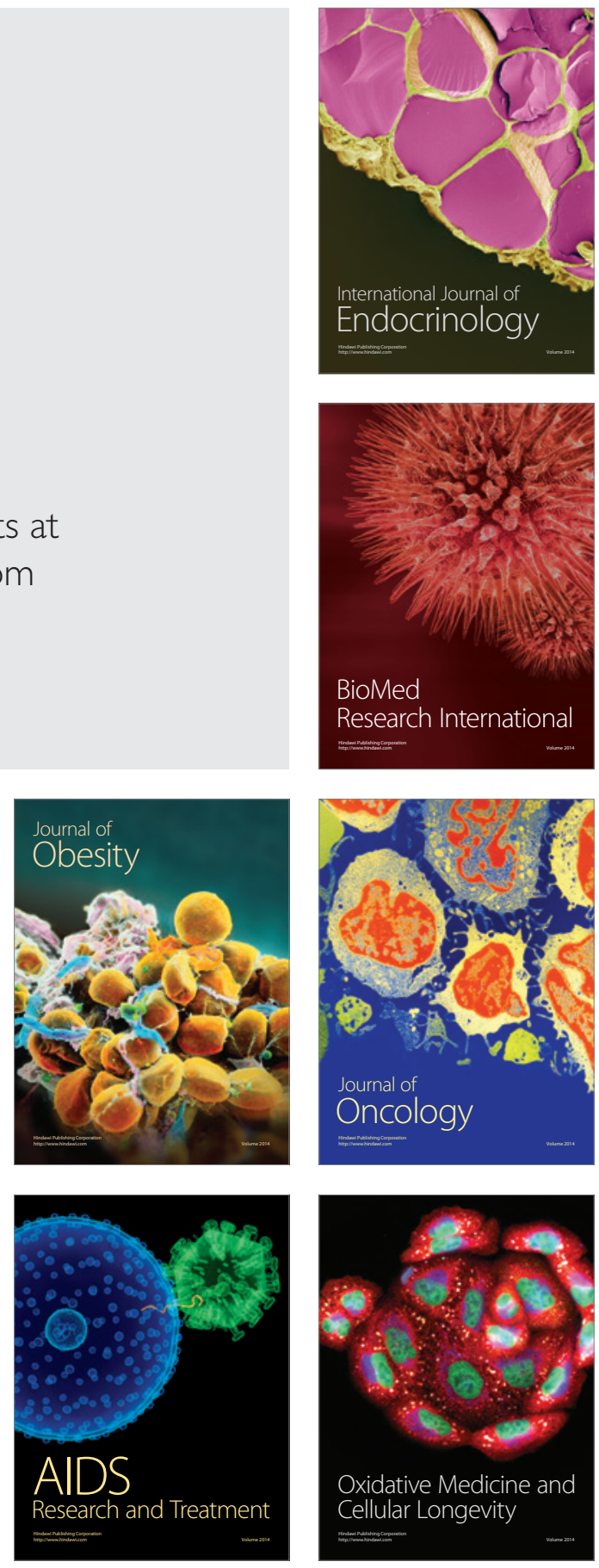